\title{
TOELAATBAARHEID VAN VORDERING UIT \\ ONGERECHTVAARDIGDE VERRIJKING IN GEVALLEN, WAARIN DEZE NIET IN DE WET IS GEREGELD. \\ VERGOEDINGSPLICHT VAN DE EIGENAAR VAN EEN PERCEEL \\ TEGENOVER DE AANNEMER, DIE KRACHTENS OPDRACHT \\ VAN EEN DERDE OP HET PERCEEL HEEFT GEBOUWD \\ (H.R. 30 jan. 1959, NJ 59, 548)
}

door Prof. Mr. J. H. Beekbuis

Sinds Bregstein in zijn proefschrift en latere W.P.N.R. artikelen (4043-4046 en 4300 ) het bestaan in ons recht heeft verdedigd van een algemene actie, die tot strekking zou hebben de verrijking, die iemand zonder redelijke grond ten koste van het vermogen van een ander genoten heeft, ongedaan te maken, is de belangstelling voor dit onderwerp hand over hand toegenomen. Vele nieuwere schrijvers, zoals Pitlo (ad art. 1395, lid 1); Völlmar (no. 763); Rutten (Verbint. recht II, blz. 471) en Wiersma (in zijn bewerking van Hofmann, blz. 42) hebben zich door de beschouwingen van Bregstein doen overtuigen. Ook door de lagere rechtspraak is het bestaan van een verrijkingsactie herhaaldelijk erkend (zie Hof Amsterdam 24 okt. 1956, NJ 57, 368; Hof den Haag 22 mei 1957, NJ 57, 586). De H.R. heeft tot dusver echter de vraag nog steeds kunnen ontgaan. Weliswaar heeft Rutten naar aanleiding van het arrest van 29 juni 1956, NJ 1956, 450 in verband met een onverschuldigde betaling gedaan aan een onbevoegd vertegenwoordiger de mening verkondigd, dat de H.R. de actie uit ongerechtvaardigde verrijking reeds toen erkend zou hebben (zie de noot onder het arrest) maar deze opvatting is bestreden door Bregstein (N.J.B. 1956, blz. 827; N.J.B. 1957, blz. 217) en van Oven (Ars Aequi 56/57, blz. 36). Het is dan ook van bijzonder belang te achten, dat zich thans eindelijk een geval heeft voorgedaan, waarin de H.R. gelegenheid heeft gekregen zich over het al of niet bestaan van een verrijkingsactie uitdrukkelijk uit te spreken.

De feiten, die aan het geding, dat thans door de H.R. is beslist, ten grondslag lagen, waren als volgt:

De vennootschap onder firma Bouwbedrijf J. V. Quint en J. de Poel (verder Quint te noemen) bouwde krachtens een overeenkomst van aanneming en aanbesteding, gesloten tussen haar als aanneemster en Hubertus te Poel als aanbesteder, twee winkelhuizen c.a. op een perceel, toebehorende aan de broer van Hubertus, te weten Heinrich te Poel. De bouw geschiedde met medeweten van Heinrich, die op het perceel een crediethypotheek gevestigd had ter financiering van de bouw. Toen Hubertus niet in staat bleek te zijn het restant van de aanneemsom te betalen, stelde Quint een vordering in tegen Heinrich, welke vordering primair gegrond werd op een beweerde onrechtmatige daad van de zijde van Heinrich, en subsidiair op een ongerechtvaardigde verrijking, die aan de zijde van Heinrich zou hebben plaats gehad.

De rechtbank te Maastricht wees de primaire vordering af, omdat Quint de schade aan zichzelf te wijten had door niet de moeite te nemen vóór het sluiten van de aannemingsovereenkomst na te gaan, wie eigenaar was van het te bebouwen perceel, terwijl bovendien niet gesteld of bewezen was, dat Heinrich reeds bij het tut standkomen van de aannemingsovereenkomst op de hoogte was van de slechte 
finantiële positie van Hubertus. De subsidiaire vordering achtte de Rechtbank echter in beginsel toewijsbaar ondanks het feit, dat een algemene bepaling over ongerechtvaardigde verrijking in het $\mathrm{B}$.W. niet voorkomt.

In hoger beroep vernietigde het Gerechtshof te den Bosch het vonnis van de Rechtbank en verklaarde Quint niet ontvankelijk in de door haar ingestelde vordering. Het Hof overwoog hierbij, dat uit art. 11 A.B. ${ }^{\circ}$ art. 1269 B.W. voortvloeit, dat feiten buiten overeenkomst, waaraan de wet niet zelf het rechtsgevolg van een verbintenis verbindt, geen verbintenis in het leven kunnen roepen. De argumenten, ter verdediging van het bestaan van een actie uit ongerechtvaardigde verrijking aangevoerd (nl. de billijkheid en de vóór de invoering van het $B$.W. in Frankrijk en in het oud-vaderlands recht gegolden hebbende traditie), konden daarom volgens het $\mathrm{Hof}$ geen doel treffen.

In cassatie stelde Quint o.m., dat aan verscheidene voorschriften van het B.W. het algemeen beginsel ten grondslag ligt, dat degene, die zonder wettige grond ten koste van het vermogen van een ander is verrijkt, jegens die ander is gehouden tot betaling van een vergoeding, zodat deze verbintenis begrepen moet worden geacht onder de in de artt. 1388 en 1389 genoemde verbintenissen, welke uit kracht der wet voortvloeien, terwijl het Hof bovendien aan de artt. 11 A.B. en 1269 B.W. een te enge betekenis zou hebben toegekend. Naar aanleiding hiervan overwoog de H.R.:

„O. dat het middel in de eerste plaats stelt, dat het B.W. den regel inhoudt, dat op een ieder die zonder wettigen grond ten koste van het vermogen van een ander is verrijkt, een verbintenis rust om dien ander schadeloos te stellen tot het bedrag waarmede hij is verrijkt:

„,dat een rechtsregel van dezen inhoud niet in het Wetboek is opgenomen, doch eiseres meent, dat uit een aantal wetsbepalingen, waarin de wetgever zich klaarblijkelijk heeft laten leiden door de overweging, dat ongerechtvaardigde verrijking moet worden voorkomen, kan worden afgeleid, dat de genoemde regel algemene gelding heeft;

„dat echter uit deze artikelen niet volgt, dat het genoemde gezichtspunt naar het oordeel van den wetgever onder alle omstandigheden beslissend moet zijn en het achterwege laten van een algemenen regel in den geest van art. 2987 van het Ontwerp 1820 op het tegendeel wijst;

„dat niet onmogelijk moet worden geacht, dat de wetgever zich van het geven van een algemenen regel heeft onthouden, omdat de toepassing daarvan in sommige gevallen tot ongewenste resultaten zou leiden, waarbij in het bijzonder kan worden gedacht aan de mogelijkheid, dat een schuldeiser zich langs dezen weg boven andere schuldeisers zou bevoordelen, of aan de mogelijkheid, dat iemand, wien tegen zijn wil een vermogensrechteliik voordeel is opgedrongen, verplicht zou worden dit door betaling van een geldsom ongedaan te maken:

,dat eiseres zich bij de mondelinge toelichting heeft beroepen op een traditie die in Frankriik en ten onzent vóór de invoering van de codificatie zou hebben bestaan; „dat zich inderdaad het geval laat denken, dat een onder het vroegere recht algemeen aanvaarde rechtsregel, welke door het Wetboek ndch uitdrukkeliik aanvaard, nòch uitdrukkeliik verworpen is, na de invoering van het Wetboek bliift voortleven, en deze regel alsdan krachtens de traditie als geldend recht moet worden aanvaard;

.,dat zodanig geval zich echter te dezen niet voordoet;

$\mathrm{m}$ a b blz. 121 
„dat immers, daargelaten of het vóór de invoering van het Wetboek de gangbare opvatting is geweest, dat naast de bronnen van verbintenis die het Romeins recht kende, de ongerechtvaardigde verrijking als zelfstandige bron van verbintenis moet worden erkend, deze traditie zich in ieder geval na de invoering van het Wetboek niet heeft voortgezet;

„O. dat het middel voorts aan het Hof verwijt zijn beslissing te hebben doen steunen op een onjuiste uitlegging van art. $11 \mathrm{~A}$.B.;

„dat deze grief geen zelfstandige betekenis heeft omdat, indien art. 1269 B.W. een uitputtende regeling geeft van de bronnen der verbintenis, art. 11 den rechter verbiedt dezen regel als niet-uitputtend aan te merken;

„O. dat het middel zich eveneens richt tegen de door het Hof aan art. 1269 gegeven uitlegging;

„O. daaromtrent:

dat aan het Hof kan worden toegegeven, dat de door art. 1269 gegeven regeling niet toelaat om aan te nemen, dat tussen twee personen een verbintenis ontstaat in alle gevallen, waarin naar het oordeel van den rechter de redelijkheid of de billijkheid verlangt, dat de een tegenover den ander een zekere prestatie verricht;

„dat echter het Hof door, na te hebben bevonden dat het door Quint gepretendeerde vorderingsrecht niet in een bepaald wetsartikel steun vindt, daaraan de gevolgtrekking te verbinden, dat aan Quint geen vorderingsrecht toekomt, een te enge uitlegging heeft gegeven aan de woorden ,uit de wet";

„dat uit deze woorden immers geenszins volgt, dat elke verbintenis rechtstreeks op enig wetsartikel moet steunen, doch daaruit slechts mag worden afgeleid, dat in gevallen, die niet bepaaldelijk door de wet zijn geregeld, de oplossing moet worden aanvaard, die in het stelsel van de wet past en aansluit bij de wèl in de wet geregelde gevallen;

„dat thans moet worden onderzocht, of in het onderhavige geval een verbintenis tussen partijen geacht kan worden in den hierboven bedoelden zin ,uit de wet" te zijn ontstaan;

„O. daaromtrent:

dat zich te dezen de vraag voordoet of op den eigenaar van een on roerend goed, die door toepasselijkheid van den natrekkingsregel is verrijkt, de verplichting rust om tot het bedrag zijner verrijking dengene, die de werken heeft aangelegd, schadeloos te stellen;

,,dat de wet daarover regelingen heeft getroffen voor het geval, dat werken zijn aangelegd door een beperkt zakelijk gerechtigde (artt. 762, 772 en 826), doch deze - onderling afwijkende - regelingen, die samenhangen met den bijzonderen aard van de zakelijke rechten, waarop zij betrekking hebben, te dezen niet van beslissend belang kunnen zijn;

„dat echter blijkens de art. 658 en 1603 van den grondeigenaar niet kan worden gevergd, dat hij door betaling van een geldsbedrag de verrijking ongedaan maakt, die hij heeft genoten, doordat de bezitter of de huurder van den grond daarop werken heeft aangelegd;

„dat onaannemelijk is, dat een aanspraak, die de wet aan den bezitter en aan den huurder onthoudt, zou toekomen aan den aannemer, die ter uitvoering van een met den huurder aangegane overeenkomst werken heeft aangelegd, en die schade liidt doordat zijn medecontrartant niet tot betaling in staat bliikt te zijn; „dat hieraan het in art. 659 bepaalde niet afdoet, aangezien een bijzondere be- 
scherming, gelijk aan die van den bezitter te goeder trouw, niet toekomt aan Quint, die, hoewel zij door tijdig de openbare registers te raadplegen had kunnen weten, dat zij ging bouwen op grond, die niet aan haar opdrachtgever toebehoorde, daarvan naar haar eigen stellingen eerst na afloop van den bouw heeft kennisgenomen;

O. dat, nu uit het bovenstaande volgt, dat het Hof terecht - zij het niet op juiste gronden - Quint niet-ontvankelijk heeft verklaard in haar vordering, het cassatiemiddel niet kan slagen;"

Verwerpt het beroep.

Bij beschouwing van bovenstaand arrest dient in de eerste plaats opgemerkt te worden, dat het wel bijzonder gelukkig is te achten, dat de vorm, waarin het Hof zijn beslissing heeft gekleed, de H.R. gelegenheid heeft gegeven over deze brandende twistvraag een oordeel te geven. Had het Hof zich beperkt tot de stelling, dat een verrijkingsactie niet enkel op grond van billijkheid en de vóbr 1838 bestaande traditie zou mogen worden aangenomen, dan zou het moeilijk geweest zijn een artikel aan te wijzen, dat door deze beslissing zou zijn geschonden. Weliswaar heeft de eiser in cassatie in dit verband de artt. 1388 en 1389 genoemd, maar volgens H.R. dec. 1946, N.J. 1947, 139, zijn deze bepalingen slechts van leerstellige aard, zodat er geen cassatiemiddel op kan worden gebouwd. Bovendien leidt vergelijking met het Franse recht (art. 1370 C.C.) er - gezien de bewoordingen van art. 1389 - eerder toe geen acties uit rechtmatige daad buiren de wet om te erkennen dan het omgekeerde (anders Bregstein, W.P.N.R. 4300, die zich beroept op het feit, dat onze wetgever zich blijkens Voorduin V, blz. 71, bii de opstelling van de artt. 1388 en 1389 heeft laten leiden door Toullier, Droit Civil XI, $\$ 14$ e.v., alwaar uitdrukkelijk van ongerechtvaardigde verrijking wordt gesproken).

Het Hof heeft het de H.R. echter in zekere zin gemakkelijk gemaakt, doordat het zijn oordeel ook gebaseerd heeft op de betekenis van de artt. 11 A.B. en 1269 B.W. Volgens het Hof staat het de rechter ingevolge art. 11 A.B. niet vrii verbintenissen te creëren, welke niet door de Wet gegeven en geregeld zijn, terwijl art. 1269 B.W. uitputtend voorschrijft, op welke wijze verbintenissen kunnen ontstaan. Gegeven deze uitspraak kreeg de H.R. een aanknopingspunt voor cassatie. Mochten er immers wel verbintenissen bestaan buiten de door de wet genoemde, dan zou het Hof in ieder geval art. 1269 geschonden hebben.

Wat dit punt betreft is de H.R. nu van oordeel, dat uit art. 1269 geenszins mag worden afgeleid, dat elke verbintenis rechtstreeks op enig wetsartikel moet steunen. Inderdaad is een andere beslissing moeilijk denkbaar, gezien het feit, dat zowel in rechtspraak als literatuur tal van verbintenissen worden erkend, die niet als zodanig door de wet worden genoemd (zie Asser-Rutten I, blz. 57 e.v.). Men denke bv. aan regres-acties tegen degenen, die mede een onrechtmatige daad hebben gepleegd (laatstelijk H.R. 4 nov. 1955, N.J. 1956, 1); regres-vorderingen van degenen, die voor een onrechtmatige daad van een ander aansprakelijk zijn tegen die ander (Asser-Rutten II, blz. 560); de vordering van de schuldeiser tegen degeen aan wie de schuldenaar ingevolge art. 1422 bevriidend heeft betaald (Asser-Rutten I, blz. 339). Uit dit alles volgt volgens de H.R. echter niet dat tussen twee personen reeds dan een verbintenis ontstaat, zodra de redeliikheid of de billijkheid dit vordert: slechts indien de verbintenis tevens in het stelsel van de wet past en aansluit bij de wel in de wet geregelde gevallen zou de rechter het bestaan ervan mogen aannemen. In dat geval is de verbintenis dan voortgevloeid ,,uit de wet" in ruimen zin genomen.

m a b blz. 123 
De vraag, die de H.R. zich moest stellen, was dus, of ook de verbintenis uit ongerechtvaardigde verrijking als een zodanige, in het stelsel van de wet passende en bij de wel in de wet geregelde gevallen aansluitende" verbintenis kan worden beschouwd. Deze vraag is door de H.R. in het algemeen in ontkennende zin beantwoord. Uit de talrijke wetsbepalingen, waaraan de gedachte van ongerechtvaardigde verrijking ten grondslag ligt, mag volgens het College geen regel van algemene gelding worden afgeleid. In dezelfde zin H. Drion in W.P.N.R. 4606. Het argument, waarop de H.R. zich voor deze stelling beroept (het niet opnemen van een algemene regel in het B.W. in de geest van art. 2987 van het ontwerp 1820) lijkt niet sterk: uit de wetsgeschiedenis blijkt immers duidelijk, dat onze wetgever zich in deze materie geheel heeft laten leiden door het Franse recht (Bregstein, W.P.N.R. 4300). Evenmin maakt op mij veel indruk de overweging, dat de toepassing van een algemene verrijkingsregel tot ongewenste resultaten zou kunnen leiden i.v.m. de mogelijkheid, dat een schuldeiser zich langs deze weg boven andere schuldeisers zou bevoordelen (kennelijk is hier gedacht aan gevallen, als genoemd in de dissertatie van Bregstein, blz. 35 e.v. en 239 e.v.) of de mogelijkheid, dat iemand, aan wie tegen zijn wil een vermogensrechtelijk voordeel is opgedrongen, verplicht zou worden dit door betaling van een geldsom ongedaan te maken (b.v. indien iemand zonder enige noodzaak de schuld van een ander betaalt.) In al deze gevallen kan men ongewenste resultaten vermijden door de verrijking niet als ongerechtvaardigd te beschouwen. De verwerping tenslotte van het beroep van de eiser in cassatie op de traditie, die in Frankrijk en ten onzent vóór de invoering van de codificatie zou hebben bestaan, op grond van het feit, dat deze traditie zich niet zou hebben voortgezet (over het buitenlands recht, waarin de regel vrijwel algemeen erkenning vindt, wordt niet gerept) acht ik al evenmin overtuigend, indien men dit arrest legt naast dat van 21 mei 1943, N.J. 43, 455 i.v.m. de vraag, of bij kwetsing recht bestaat op vergoeding van z.g. ideële schade.

Hoe dit alles ook zij, de H.R. heeft niet zover willen gaan, dat het College elke actie uit ongerechtvaardigde verrijking buiten de wet om heeft willen afsnijden. Slechts moet worden onderzocht, of het aannemen van een verbintenis in het bepaalde geval past in het stelsel van de wet en aansluit bij de wèl in de wet geregelde gevallen. Als een van die gevallen beschouwt de H.R. kennelijk het bouwen op eens anders grond, omdat hiervoor een regeling gegeven wordt in de artt. $656 j^{\circ}$ 658 en $659 \mathrm{~B}$.W., zij het, dat deze regeling niet volledig is, (zie in dit verband Hof den Haag 22 mei 1957, N.J. 57, 586, waarin een vergoedingsplicht is aangenomen buiten de regeling van art. 658 en 659 om). Als tweede voorbeeld van een verrijkingsactie, die in de wet is geregeld, maar daarbuiten kan worden uitgebreid, kan men noemen de regeling van onverschuldigde betaling (art. 1395). Niet alleen wordt het woord ,betalen" in vermelde bepaling in strijd met de oorspronkelijke betekenis (het voldoen aan een verplichting om te geven) opgevat als het voldoen aan elke verbintenis (zie H.R. 7 nov. 1935, N.J. 36, 239), maar bovendien wordt de actie toegekend aan personen, die zelf in het geheel niet betaald hebben, alleén, omdat de betaling te hunnen laste is gekomen en de ontvanger door de betaling dus te hunnen koste is verrijkt (zie H.R. 25 iuni 1869, W. 3131; 22 mei 1885, W. 5175; 11 nov. 1955. N.T. 57, 605, Ars Aequi 57/58, 122). Omgekeerd zou men de condictio indebiti ook kunnen toekennen tegen degeen, die uiteindelijk van de onverschuldigde betaling voordeel heeft genoten, al is de betaling niet aan hem zelf geschied. Men verg. verder over deze materie Bregstein diss. blz. 267 e.v. en W.P.N.R. 4046.

m a b blz. 124 
Ik kom thans tot de rechtsvraag, waar het in het onderhavige geval om ging. Een aannemer heeft gebouwd op grond, die niet aan de aanbesteder toebehoort. Op de aanbesteder bestaat geen verhaal. Mag nu de aannemer de eigenaar van de grond aanspreken voor het bedrag, waarmee deze is verrijkt? Bregstein beantwoordt deze vraag bevestigend. Zie diss., blz. 138 e.v. De H.R. komt echter in het onderhavige geval tot een ander resultaat. Volgens het College dient men bij de beantwoording van de vraag voorop te stellen, dat volgens de wet van een grondeigenaar niet gevergd kan worden, dat hij door betaling van een geldsbedrag de verrijking, die hij door het bouwen van een ander genoten heeft, ongedaan maakt. Dit volgt voor de bezitter uit art. 658, voor de huurder uit art. 1603. Op dit beginsel wordt echter een uitzondering gemaakt in art. 659 ten behoeve van een bezitter te goeder trouw. De H.R. is kennelijk bereid deze uitzondering ook toe te passen op een aannemer, die te goeder trouw gebouwd heeft en geen enkel verhaal heeft op de aanbesteder, maar in casu acht het College geen goede trouw van de aannemer aanwezig, omdat deze door raadpleging van de openbare registers had kunnen weten, dat hij ging bouwen op grond, die niet aan de aanbesteder toebehoorde.

Het valt m.i. niet te ontkennen, dat deze beslissing in het onderhavige geval tot een weinig bevredigende uitkomst leidt. Weliswaar heeft de H.R. ook reeds in een vroeger arrest beslist, dat in geval van onbekendheid met feiten, die op een door de wet voorgeschreven wijze zijn gepubliceerd, in beginsel geen beroep op goede trouw kan worden gedaan (zie HR 18 april 1947, N.J. 48, 447), maar Meijers heeft er in zijn noot m.i. terecht op gewezen, dat men bij de toepassing van deze regel uiterst voorzichtig moet zijn en dat men rekening moet houden met wat in de praktijk gebruikelijk is. Zie in dit verband ook H.R. 28 febr. 1958, N.J. 58, 279 , waarover Wiarda W.P.N.R. 4567/68. In het geval van bouwen door een aannemer op grond die niet aan de aanbesteder toebehoort, mag men de regel m.i. niet zonder meer toepassen, omdat raadpleging van de registers door aannemers voorzover mij bekend is weinig gebruikelijk is. Het Ontw. B.W. heeft de regel dan ook alleen opgenomen voor de verkrijger van registergoederen (art. 3.1.2.6). Hieruit volgt, dat of in casu de aannemer geacht kan worden te kwader trouw te hebben gehandeld geheel afhankelijk is van de bijzondere omstandigheden van het geval, zodat de H.R. m.i. niet enkel op grond van het niet raadplegen van de registers tot $\mathrm{kwade}$ trouw had mogen besluiten.

Belangrijker is echter een tweede bezwaar dat ik tegen de beslissing van de H.R. zou willen aanvoeren. Uitgangspunt van deze beslissing is, dat uit de artt. 658 en 1603 zou volgen, dat van de grondeigenaar niet kan worden gevergd, dat hij door betaling van een geldsbedrag zijn verrijking ongedaan maakt. Op zichzelf is dit juist, maar uit de genoemde bepalingen is ook af te leiden, dat volgens de bedoeling van de wet de grondeigenaar niet gerechtigd is zonder meer het gebouwde te behouden. In art. 1603 wordt immers de huurder het recht toegekend de aangebrachte verbeteringen tot zich te nemen, terwijl in art. 658 aan de eigenaar een schadevergoedingsplicht wordt opgelegd, wanneer hij van zijn recht om afbraak te vorderen geen gebruik maakt. In het onderhavige geval kan echter de aannemer zelf geen wegneming vorderen, terwijl zijn vordering tot vergoeding door de H.R. is afgewezen, hoewel de eigenaar het gebouw behoudt. Van een ongedaan maken van de verrijking op de wijze, zoals geregeld is in de artt. 658 en 1603 is dus geen sprake. Door Veegens wordt dit in zijn noot onder het arrest in de N.J. betwist. 
Volgens hem had de aannemer tot gunstiger resultaten kunnen komen door in plaats van schadevergoeding afbraak van het gebouw te vorderen, in welk geval hij de bouwstoffen voor zich zou kunnen behouden. Hij leidt dit af uit het feit, dat de actie uit ongerechtvaardigde verrijking primair zou strekken tot teruggave in natura, in casu dus tot afbraak. Afgezien van het feit, dat toekenning van een actie tot afbraak in het onderhavige geval wel tot zeer onpraktische resultaten zou leiden, geeft de wet aan deze opvatting echter niet de minste steun. Uit verschillende bepalingen volgt juist, dat de eigenaar niet gedwongen kan worden gebouwen, die vervaardigd zijn met bouwstoffen van een ander, weer af te breken. Men verg. behalve art. 658 b.v. art. 657 , handelende over het geval, dat de eigenaar gebouwd heeft met bouwstoffen, die niet aan hem toebehoorden.

M.i. bieden de artikelen 658 en 1603 B.W. daarom weinig houvast voor de beantwoording van de vraag, die aan de H.R. werd voorgelegd. Omgekeerd zou ik ook niet uit art. 659 B.W. willen afleiden, dat de aannemer, die te goeder trouw gehandeld heeft wel vergoeding kan vragen. Want indien men een vordering van de aannemer in dat geval mogelijk acht, dan draagt deze vordering toch in ieder geval, in tegenstelling tot het recht, dat uit art. $659 \mathrm{~B}$.W. voortvloeit, een subsidiair karakter, d.w.z. dat van toewijzing van de vordering slechts sprake kan zijn, indien de aannemer op zijn opdrachtgever tengevolge van diens insolventie geen verhaal heeft. De verrijkingsactie verschilt in dit opzicht principieel van het recht op vergoeding ingevolge art. $659 \mathrm{~B} . \mathrm{W}$.

Het verdient overigens nog vermelding, dat de Franse jurisprudentie in situaties als waarom het hier ging een verrijkingsactie in beginsel wel mogelijk acht. Men verg. het arrest van de Cour de Cassation van 11 september 1940, S. 1941.1.121, in welk arrest tevens duidelijk het subsidiair karakter van de vordering naar voren is gebracht. Dit geldt echter niet, wanneer door een huurder gebouwd is en het contract met de verhuurder een bepaling inhoudt, dat laatstgenoemde recht heeft op alle door de huurder aangebrachte verbeteringen zonder dat hij daarvoor vergoeding verschuldigd is. (Cour de Cassation 12 februari 1923, D. 1923.1.64. In dat geval is er voor de verrijking immers wel degelijk een rechtsgrond aan te wijzen. 